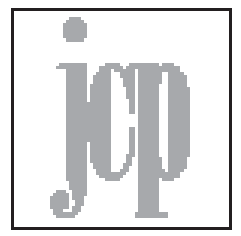

\title{
Bio-Colonial Co-Optation of Knowledge: An Eco-Imperialist Investigation of Anita Desai's TheVillage by the Sea and Uzma Aslam Khan's Thinner than Skin
}

\author{
Saadia Neelam Ali \\ Independent Scholar \\ sna2009sna@gmail.com
}

\begin{abstract}
My paper investigates the neo-orientalist discourse of eco-imperialism and postulates that eco-imperialism deploys biopiracy and bio-colonialism in order to subjugate the Global South while privileging the Global North. Using Uzma Aslam Khan's Thinner than Skin and Anita Desai's The Village by the Sea as sites of analysis, my study highlights eco-imperialist modes of subjugation in the texts with particular emphasis on knowledge production. Taking an interdisciplinary route, I have blended the pertinent theoretical concepts of Vandana Shiva and Laurelyn Whitt and inferred that eco-imperialism operates through the construction of an 'authentic knowledge' in which Western knowledges are privileged over non-Western knowledges. This involves the robbing of Indigenous knowledges and employing them as a commodity frontier through which the West profits off knowledge collected from developing nations while perpetuating western supremacy. My paper further explores, through the selected texts, the construction and projection of a reductive homogenised subjectivity on the inhabitants of the Global South by the environmentalist narrative, which does not only overlook their cultural specificities but also ignores the nuanced relationship individuals have with their environment.
\end{abstract}

Keywords: Biopiracy, bio-colonialism, eco-imperialism, knowledge production, homogenised subjectivity, South Asian Anglophone Literature 


\section{Introduction}

In this paper, I set out to investigate how biopiracy and bio-colonialism operate in conjunction with eco-imperialism to perpetuate a new form of domination that employs universalising and homogenising narratives of global ecological preservation. I argue that eco-imperialism is deployed by the Global North in order to dominate the Global South. In order to achieve this, I set out to explore how this form of domination is primarily carried out through the construction of knowledge about the ecology of the Global South which then serves as a tool through which power is exerted by the Global North over these nations. ${ }^{1}$ My key contention is that capitalism, a Eurocentric ideology, co-opts disciplines such as science to advance its own economic gains, subsequently leading to the economic advancement of the West. It employs science as a way of sanctioning its domineering and oppressive positionality and also as a way of legitimising the superiority of Western cultures over non-western cultures. ${ }^{2}$

In order to conduct this investigation, I have chosen two South Asian anglophone novels, that is, Thinner than Skin by Uzma Aslam Khan (Pakistan) and TheVillage by the Sea by Anita Desai (India). These texts allow for the study to zoom in on the interplay of bio-colonialism and biopiracy in furthering eco-imperialist goals in the South Asian context which is in dire need of ecologically conscious reforms due to pervasive environmental issues. By focusing its attention on foreign bio-colonial interventions in Pakistan and India as depicted in the selected texts, my paper unveils the capitalist intentions of the eco-imperialist agenda. By eco-imperialism I imply new means of extending economic and epistemic power, for instance, through multinational organisations which use covert narratives of eco-consciousness and environmentalism instead of military force in order to further their capitalist interests.

With the rise of environmental issues such as global warming, melting polar caps, unusual weather, patterns, etc., environmental preservation projects have taken the centre stage in most ecological debates. I believe that environmental preservation has become an imperial tool that is employed for the reassertion of Western capitalist supremacy over many non-Western nations. It has now taken the form of bio-colonialism and biopiracy in which it is life and liferelated resources that are colonised while perpetuating colonial thinking wherein

1 Originally coined by French demographer Alfred Sauvy in 1952, the term 'tiers monde' ('Third World') referred to countries outside the two major power blocs of the West (first world) and the Soviet Union (second world).

2 See Ramón Grosfoguel's “The Epistemic Decolonial Turn: Beyond Political-Economy Paradigms” and Walter Mignolo's “Epistemic Disobedience, Independent Thought and Decolonial Freedom” for a more insightful analysis of the role of science as a tool of colonialism. 
the West exercises its domination over non-western nations. The term biopiracy comes from Vandana Shiva and implies the robbery of biological resources and its related Indigenous knowledge of biodiversity. In Biopiracy: The Plunder of Nature and Knowledge, Shiva has written extensively about biopiracy, which she has come to see as the next step in an ongoing technological revolution that continues to exploit nature and Indigenous people, in particular, their systems of knowledge production in relation to biodiversity. For this paper, I define biopiracy as the co-optation of native knowledge about the environment by different global conglomerates and its utilisation against the interests of the natives. I foreground how this serves as a way of perpetuating a new form of imperialism and exploitation of Indigenous cultures across the world.

In line with Shiva, Laurelyn Whitt takes the idea of biopiracy further and links it with colonialism by devising the term "bio-colonialism", which refers to the domination of the Western scientific discourses over populations of the Global South through scientific policies (33). In Science, Colonialism, and Indigenous Peoples: The Cultural Politics of Law and Knowledge, she has taken up the matter of the continued exploitation of Indigenous knowledge systems. She argues that bio-colonialism is no different from the previous modes of colonial domination and that this is merely a "continuation of the oppressive power relations that have historically informed the interactions of Western and Indigenous cultures, and part of a continuum of contemporary practices that constitute forms of cultural imperialism" (1). This suggests that neo-colonialism now operates through the domination of the biodiversity of a nation which, according to Shiva, has "always been a local common resource" (67). This domination is justified by the argument that the act of biopiracy is a necessity for benefitting and further developing the countries of the Global South. It is for this reason that in my paper I set out to investigate the ways biopiracy and bio-colonialism are enacted in Pakistan and India via their depictions in Khan's and Desai's novels.

Khan's Thinner than Skin, written in 2012, recounts the journey of two Pakistani-Americans, Farhana and Nadir. Both these characters, along with their friends go to the glaciers of the northern areas of Pakistan where they meet different members of the nomad community residing among the glaciers, two of them being Mariam and her daughter Kiran. In this novel, the love story of Farhana and Nadir is accompanied by the very palpable role played by the environment throughout the novel. Farhana and Nadir's decision to visit Pakistan is linked to the environment, that is, to study the glaciers in the case of Farhana, and to take photographs of the unique landscapes in Nadir's case. 
Comparably, Desai's The Village by the Sea, written in 1982, is the story of a brother and a sister, Hari and Lila, who live in a village called Thul which is surrounded by natural beauty. ${ }^{3}$ It is a place of pure natural beauty and peace. Desai gives a beautiful picture of the biodiversity of the place, its various species of birds and animals, and the dense greenery of Thul. This novel recounts the struggles faced by its people especially when the village is set to become the site of a fertiliser factory unit. The novel thus depicts the changes a village undergoes when it moves away from modes of production that were agricultural to more industrialised ones. Therefore, what we see is that both Desai and Khan highlight, in their novels, the ways in which the environmental discourse is operational in the Global South in furthering the capitalist interests of the Global North.

There are several reasons for my selection of these writers. First and foremost, both the texts depict the characters in close connection with their environment. This connection is then disrupted by factors which are not of native origin. Moreover, these texts span across India and Pakistan as well as the United States. In the contexts depicted by these texts, the notion of eco-imperialism gains significance since it illustrates the ways imperialism has evolved into a more discrete form of domination today via eco-imperialism. My study focuses on these specific issues of eco-imperialism and it explores them in relation to biocolonialism and biopiracy through the selected novels.

This paper takes on a qualitative approach to investigate the perpetuation of eco-imperialism in Pakistan and India through the narrative analysis and close textual analysis of Khan's Thinner than Skin and Desai's TheVillage by the Sea. As I foreground the two primary theoretical strains, that is, biopiracy and biocolonialism, I read these alongside environment conservation efforts made in the novels. I suggest that these conservation efforts enact forms of domination as they not only offer an ecological discourse which is universalised and homogenised but, in doing so, they also replicate the imperialist discourse of 'us' vs 'them' in which the ecological knowledge of non-Western countries is presented as inauthentic.

My eco-imperialist critique of the global narratives of environmental conservation is necessary because I believe it to be a mode of resistance towards the ways eco-imperialism is being propagated. This research, along with the selected novels, become sites of contestation. They contest the false and dangerous universalising tendencies of bio-colonialism and its nexus with international capitalist conglomerates. A glaring example of this is the way Monsanto, an American agrochemical and agricultural biotechnology corporation has, to a certain ex3 Thul is a real village on the Western coast of India, some fourteen kilometres away from Mumbai. 
tent, monopolised the modern agricultural scene in the international market. Monsanto dominates the agricultural business through the patenting of its seeds (Bhardwaj and Jadhav n.d.). This has had a devastating effect on farmers, as has been seen in India in the recent years where cotton farmers have been facing serious difficulties making their ends meet as Monsanto controls 95 percent of the cotton seed market through its genetically modified organisms, that is, GMOs ("How Monsanto"). This, along with a poor implementation of government policies, has led to the rising number of suicide cases among Indian cotton farmers.

\section{The Production of Knowledge and its Role in Bio-Colonialism}

Many writers such as Madina Tlostanova and Walter Mignolo have expounded on the evolution of colonialism into neo-colonialism. They have attempted to understand the different ways neo-colonialism is still operating in the former colonies in the Global South. Nelson Maldonado-Torres recognises that although the traditional form of colonialism, which entailed physical domination along with the use of force, has ceased to exist, however in the contemporary era, colonial modes of subjectivation ${ }^{4}$ have now been interwoven in the administration, knowledge, culture and religion of the former colonies through the rhetoric of modernity. Thus, in the context of this paper, neo-colonialism entails the end of a particular mode of colonialism which then shifts its gears and evolves to another stage, one that relies less on physical domination and more on ideological forms of exercising power over the nations of the Global South. This shift in the forms colonialism can take, allows for the establishment of the connection between colonialism, neo-colonialism and bio-colonialism.

To further substantiate this idea of how neo-colonialism is still operational in the Global South, Tlostanova and Mignolo argue that colonialism exerted its power through four spheres, namely: the struggle for economic control, the control of authority, the control of the public realm and the control and domination of knowledge and subjectivity. As discussed earlier, Mignolo argues that while the First World has knowledge, the Third World has culture (2). It is the knowledge possessed by the First World which is further problematised by Ramón Grosfoguel, according to whom, the West holds knowledge as something that is objective, universal, modern, and neutral. For him, this notion is a myth. He argues that knowledge is mythologised through the concealment of the "speaker" as well as the location of this speaker (Grosfoguel 213). In the context of my paper, the speaker here can be understood as the knowledge producing tool. By hiding the speaker and consequently the source of knowledge, the West can present an un4 Notion originally presented by Michael Foucault to describe the process by which one becomes a subject. 
fixed and non-localised knowledge that can then conceal its Eurocentric agenda. This concealment of the speaker's location allows for science to be conceived as if it were presented by a universal voice or what Santiago Castro-Gómez terms as "point zero" (1) which presents a god-eyed point of view. It is interesting to note that by calling it a god-eyed point of view, Castro-Gómez evokes the idea of an omnipresent and all-knowing voice which further substantiates the idea of its being unquestionable and authentic and a voice that cannot be demystified. I take up the idea that Western knowledge is presented to the Global South by the Global North from a god-eyed point of view to explore the ways Western knowledge discards, replaces and at times assimilates the Indigenous knowledges. Bio-colonialism and biopiracy employ this decentred and speaker-less Western knowledge to invalidate Indigenous knowledges as well as to perpetuate global narratives of ecological conservation which are inherently complicit with the capitalist interests of the Global North. These in turn allow for the perpetuation of Eurocentric domination over the Global South. Shiva argues that biopiracy operates through the appropriation of Indigenous knowledge for transnational corporations thus creating a "monoculture of knowledge" (Biopiracy 9). I contend that while it does create a monoculture of knowledge, as Shiva says, this new homogenised culture operates on the narrative of Eurocentrism whereby it asserts the supremacy or dominance of the West over the rest of the world.

In Thinner than Skin and The Village by the Sea, we can see the ways in which Western notions of science and knowledge are regarded as not only superior to non-Western knowledges, but also more advanced and more efficient. Desai, in The Village by the Sea, highlights how the traditional ways of agriculture and cultivation are discarded in favour of Western ways as is evident through the creation of a fertiliser factory unit in the village of Thul. For the locals, this mass production of chemicals is foreign to them. When they are informed about what fertilisers are, they find it ridiculous that so much effort is being put into the making of manure as one of the villagers says, "all this vast complex, modern and scientific, to be built only to make manure for the fields?” (Desai 68). This reaction of the people indicates the subtle and discreet ways in which the bio-colonial agenda operates. It is evident that in the guise of national welfare the Western bio-colonial venture advertently furthers its own capitalist interests.

Bio-colonialism makes use of projects which outwardly seem to be working for the welfare of the locals in the Global South. Elizabeth DeLoughrey and George B. Handley in their book Postcolonial Ecologies: Literatures of the Environment make the observation that environmental concerns are not the exclusive 
prerogative of the privileged Global North. Rather, history has demonstrated how postcolonial nations have been impacted by the environmentalist discourse and practices of the West in the form of schemes enforced by the IMF and the World Bank and how resource extraction initiatives like deforestation, mining, and the liberalisation of internal markets have all radically altered postcolonial environments.

There are several tropes which lead to eco-imperialism through bio-colonialism. Bio-colonialism employs tropes such as environmentalism to relegate the Global South to the position of the marginal while perpetuating the hold of the Global North over the Global South. This occurs via the penetration of multinational companies and organisations, mostly headquartered in the Global North, into the Global South. Governmental structures in the Global South also, at times, become complicit with the capitalist agenda of the Global North as they introduce certain policies which, instead of working for the welfare of the people, end up causing more environmental damage. An example of this is the Green Revolution of India and Pakistan, introduced by the countries' respective governments in the 1960s. This revolution aimed at making the agricultural industry more efficient through the adoption of different modern methods and technologies such as the use of high yielding variety (HYV) seeds, tractors, irrigation facilities, pesticides, and fertiliser (Rowlatt). In India, this movement was a joint attempt made by several international donor agencies and the Government of India in order to begin a "new capital-intensive agricultural development" in selected parts of the country (Dutta 230). The social, economic and environmental effects of the Green Revolution are still very much visible in today's India where 250 thousand debt-ridden farmers killed themselves while 800 million are impoverished (Roy 565). It also caused a massive decrease in the fertility of the land due to the overuse of land consequently leading to a lower yield of crops in the subsequent years.

What these facts highlight is that policies such as these do not take into account the interests of the locals; instead they work for the propagation and advancement of the capitalist interests by focusing on the maximisation of profits. These policies disregard the devastating effects these may have on humans and the environment. It must be noted that not all these projects are introduced by using capital invested by the Global North, local businesses and the government, at times, become complicit with the ideology of the Global North; thus, they propose policies which are inherently capitalist and consequently end up promoting Eurocentric ideals of capitalism. They work in line with capitalist interests 
despite their engaging of local people as employees. This new form of domination is what Paul Driessen refers to as "eco-imperialism" which he describes as a trope employed by the West to forcefully impose its superiority over the developing countries (13). Lim Soomin and Dr. Steven Shirley further elaborate this idea and remark on the way eco-imperialism is an extension of the colonial domination of imperialism which, instead of relying upon territorial control, has shifted to a "radical environmentalist agenda" that "seeks to reserve the earth and its resources for the wealthy and elite" (848). For that, according to Soomin and Shirley, the developed countries violate the sovereignty of the less developed countries through the imposition of Western economic ideals and belief systems onto the less developed countries. In a similar vein, both Desai and Khan highlight how several state-introduced policies, which are influenced by capitalist interests, end up failing and becoming counterproductive for the locals. For instance, in Thinner than Skin the government introduced Australian sheep which were to increase the overall meat and milk production in the northern areas of Pakistan. These sheep, which were accustomed to the Australian climate, were unable to survive the change of climate and thus failed to yield more production. The intervention of the Global North in local policies is also evident in the tale Maryam's mother recounts of the days when "timber and thatching grass had once been free. The forest department would take away materials each spring, when the families dismantled their huts and headed for the mountains, and give back the same timber each autumn, when they returned." (Khan 210) She told Maryam that, "it was the Angrez who invented this business, the whole revenue generating forest policy that bound the herders forcing them to pay a grazing fee and tree-cutting fee" (Khan 250). Before the intervention of the Angrez, "they had been free to graze and chop. And the sedentary folk had been friendly. They let the nomads camp in their fields during the migration, knowing that when the cattle moved on, they left piles of fresh, steaming dung. Free manure" (Khan 251). It was thus the intervention of the Global North which, in trying to capitalise from the local resources, had not only caused a significant monetary loss to the nomadic tribe but had also severed their friendly ties with the sedentary folks. Now, as Maryam's mother remarks, "everyone is welcome but us" (Khan 210).

On the other hand, in The Village by the Sea, it is the construction of the fertiliser factory which, while promising to provide jobs for the locals, ends up leaving thousands of people homeless and jobless. The local villagers are, throughout the novel, presented with the idea of the construction of the factory. When one of the villagers, Biju, asked what would happen to the locals when the factory 5 Angrez is an Urdu word which means white men. 
unit is built, he is told that "Like that - your village will go. In its place, factories will come up, fertiliser will be made, gas will be produced, many jobs will be created. The government says so" (Desai 101). But when asked to clarify if these locals will be provided with these jobs or not as "Fishermen and farmers are now to become factory workers? ... You mean these boys are to give up their fathers' lands and boats and go to work in factories like city people?", he is quick to reply that these jobs are only for the "engineers and mechanics who will have to be brought from elsewhere to run the factories" while the local boys will be put in a boat and sent off "to catch fish - fifty miles away" (Desai 102). This echoes what Arundhati Roy has argued in her essay "Capitalism: A Ghost Story" that "always, local people are promised that their displacement from their land and the expropriation of everything they ever had is actually part of employment generation" (566). However, the reality is far from this claim as these promises are never fulfilled and the people are forced to not only leave their lands but also to seek new means of earning livelihoods. Thus the novel also holds up for scrutiny the misleading fictions generated by the grand narratives of democratic capitalism that promise endless growth and the well-being of all.

\section{Biopiracy: Expanding the Commodity Frontier}

What this foregrounds is that even though direct colonialism has ended, the divide between the Global North and the Global South is still markedly present. In the colonial era, the main interest in extending territorial control had been commercial, as it targeted the raw materials in the colonies which William Beinart and Lotte Hughes define as "commodity frontier" which are "the results of expanding European commercial activity productive enterprises, and sometimes settlement, which targeted raw materials and land in overseas territories" (2). This "commodity frontier" was the first step toward colonialism in which the main reason behind colonisation was the abundance of this raw material which was of potential commercial benefit for the colonisers. In the contemporary age, Beinart and Hughes' notion of the "commodity frontier" can be extended to understand how the neo-liberal world, which exerts power in a globalised form of capitalism, employs information as its "raw material" (328). It is this robbing of information, that is, biopiracy, regarding the Global South which allows for the production of knowledge which ultimately is employed by the Global North to subjugate the Global South. In this section, I engage this concept to explore how the idea of the commodity frontier has equated Indigenous knowledge with its definition of raw materials and has consequently been re-deployed in the ex- 
ploitation of the Global South. This section also explores the ways non-Western knowledges are discarded on account of their being inauthentic or are distorted in order to make them conform to the orientalist narrative of the West. In order to achieve this, it makes use of different discourses, such as environmentalism, which allow for its seamless assimilation into the Global South.

The narrative of environmental conservation is co-opted by the Global North in order to gain access to the developing and underdeveloped countries. By means of an effective use of the discourse of morality, responsibility, sustainability and development, environmentalists legitimise their intrusion into the developing countries. This is evident in A Village by the Sea in which different individuals belonging to different institutions, such as the trade union leader Adarkar who is a former politician, co-opt the villagers' protest against the building of fertiliser factories for furthering their own personal and capitalist goals. A representative of a meteorological observatory, which is situated in one of the villages where the factories are to be built, comes forward to argue that the factories will affect the working of the observatory. What comes forth is that this man is using the discourse of responsibility, sustainability and development of knowledge to justify his participation in the protest against the construction of the factory. The representative claims that they should all be "proud" (Desai 135) of the observatory because it had worked "uninterrupted since 1846". Therefore, "it must be ... preserved at all cost" (Desai 136). Having been built under the colonial rule, it acts as a symbol of modernity and is a product of the colonial predecessor of today's capitalist apparatus that advocates the building of fertiliser factories. Hence, the narrative of the man representing the meteorological department runs in stark contradiction to what the villagers are protesting against. His goal of persuading the villagers to advocate for saving the observatory will inadvertently invalidate the villagers' demands to save their land from modern capitalist apparatuses. This contradiction highlights two aspects, firstly that the representative of the meteorological department is complicit with capitalist intrusion. Secondly, his effort to enlist the villagers' support to preserve the observatory contradicts the villagers' demand to protect their land from the same capitalist framework. This example highlights one of the ways in which an ecological preservation movement becomes co-opted and assimilated within the capitalist agenda in order to perpetuate western interests. The narratives of responsibility and obligation, constructed on the basis of information extrapolated in the form of the commodity frontier, serve as tools of persuasion which appeal to the people into taking actions which will, at the end of the day, protect and 
perpetuate narratives of the capitalists.

Not only do these discourses appeal to the natives' sense of responsibility, they also appeal to their desire to save their homes. For instance, the observatory is referred to as "home" to the villagers but, according to the representative of the observatory, it is "home of the world-renowned Alibagh geomagnetic observatory" (Desai 134). Here, the use of the word "home" appeals to the villagers' emotions to manipulate them into equating the plight of losing their homes with the disruption in the working of the observatory. The representative of the observatory here becomes emblematic of what Robert Cribb says is meddling justified by the West through blaming the locals for environmental destruction and assuming them to be incapable of managing their own resources effectively. Furthermore, the reluctance of the natives to understand the benefit of a mass-produced fertiliser also substantiates Cribb's argument that most locals are unable to manage resources in an effective manner. Whenever the villagers ask about the implications of the construction of the factory, they repeatedly get the same response, that is, they will be provided with more jobs. When Hari questions a man who was in Thul for the construction of the factory unit, he was rudely reprimanded with an abrupt answer: "What do you know?" (Desai 69). This question was coupled with insults like "pumpkin-heads" (Desai 70). The people of Thul are thus believed to be incapable of comprehending the importance of building this factory unit, which was supposed to make the fertiliser production process efficient and provide thousands of jobs. Ironically, it is only those who own the unit who will get rich at the expense of all the villagers who stand to lose their land, which was their sole source of income. Thus, the representatives of the factory try to create a sense of responsibility in the locals to allow for its construction on the assumption that through the construction of this unit, the people will be able to produce more fertiliser and also gain jobs. Thus, despite capitalism framing itself as an economic system that favours profit making, it now posits itself as the benefactor of the locals. In doing so, the construction of the factory disguises its commodity frontier aspect through which the land of the locals is being robbed. Although the outward goal of the fertiliser unit is to create jobs and make the fertiliser-making process more efficient, the ground reality is quite different. This is evident in a casual comment made by a cart driver to Hari in which the former made a very pertinent observation about the capitalist undertones of the construction of the factory. He wisely observes that fertiliser is a "kind of manure... cow dung and compost. But different. You have to buy it. That's right. Now we want everything to come from the shops, ready-made. No more spinning of yarn, 
no more grinding of wheat at home and no more making of cow dung cakes or compost. I don't know why. What's this new disease? Expensive, that's what it is." (Desai 120). What this comment brings to light is that the factory is being built for purely capitalist ideals. It shall capitalise on the manure-making process which originally had been in the hands of the locals and had come at no cost at all.

Similarly in Thinner than Skin, environmentalism is framed as a universal concern, beyond any national particularities. The hyphenated identities of Farhana and Nadir allow for their assimilation into the universal category of environmentalism. Their flexible identities allow them to be adjusted within the trope of environmentalism, a floating signifier (Tynan 490) functioning to further the capitalist interests of the Global North. It can be argued that the capitalist ideals engulfing Farhana and Nadir in the United States are reflected in the ways they interact with the natives of Pakistan. By default, both Farhana and Nadir belong to the corporate culture which is complicit with the capitalist economy of knowledge production. Thus, the lens through which these two characters view the locals is tainted with the shades of these capitalist ideals since it would yield knowledge for the western geologists who employ Farhana. Farhana, an outsider, comes with the belief that she possesses greater knowledge about the natural habitat she is visiting, thus exuding a sense of authority over both the environment and the natives. Her decision to take Kiran into the boat is a clear example of the blatant sense of superiority that she feels over the nomads. This sense of superiority is then dismantled when they fail to save Kiran from drowning and thereby succumb to the power of nature.

The relationship of the Indigenous communities with the world of nature surrounding them is very different from the way any 'foreigner' sees their landscapes. The nomad communities to which Maryam belongs believe that, "everything alive is movement and everything that moves is alive. Wind and water, flowers and bees" (Khan 188). Their relationship with the glaciers is not defined in terms of exchange value as we see in the case of Farhana and Wes who are there to study them or Nadir who is there to photograph them. Farhana and Nadir's decision to visit Pakistan is informed by ideals that are anthropocentric and scholarly in nature as they privilege humans over nature while also presenting some privileged humans as the saviours of nature. Nadir's use of the camera to view his surrounding is also indicative of the same privileged western gaze that views everything through a commodifying lens. His pictures become complicit with the neo-orientalising knowledge economy of the West by presenting the mountainous areas and the Indigenous inhabitants of Pakistan's north as exotic entities. 
His camera thus becomes a tool for the commodity frontier which allows for the robbing of information regarding the Global South; knowledge which will then be employed to dominate it.

Through eco-imperialist tropes, bio-colonialism thus makes use of knowledge production deployed by international organisations, such as those Farhana and Nadir are associated with to promote their capitalist agenda. Farhana's position as an environmental scientist is subsumed into the imperialist tendencies of the Global North because the organisation she works for is a part of the knowledge-producing economy. As a subject who lived in a capitalist society, she becomes complicit with the bio-colonial agenda as she patronises the locals. Upon viewing the nomadic young girl, Farhana comments that she is "beautiful" to which Nadir replies that, "she would be, if she were better taken care of". Farhana further scolds Nadir by saying, "You should have told me, I would have brought some supplies" such as food, etc. (Khan 66). This reflects how Farhana is viewing the young girl from the perspective of a saviour, although in reality, neither the young girl nor the rest of her tribe are in any need of their assistance. This is reinforced by Nadir's remark about the natives: "They're naturally warlike and deceitful when not on your side, naturally brave and loyal when on your side" (Khan 66). He knows full well that "that girl doesn't need Farhana" (Khan 66). It is thus Farhana who needs the girl to fulfil the humanitarian task required of her as a representative of the West. Farhana's scientific expertise, gained primarily in the United States, makes her the representative of what Beinart and Hughes refer to as "colonial science" (17). Beinart and Hughes argue that scientific knowledge is often wedded together with the ideas not only of the West but also with the knowledge collected by the natives, thus, making this colonial science a commodity frontier which allows for the perpetuation of the subjugation of the Global South. Farhana's research is geared towards adding to the western bodies of knowledge. Therefore, her scientific knowledge is co-opted by the Global North for the legitimisation of its intellectual domination over the Global South. Thus, she becomes a disciple of the discourse of science and consequently aids in its legitimisation as the most authentic and universal source of knowledge.

This idea of universality is not restricted to the domain of knowledge alone; it is also reflected in the assimilation of different people belonging to diverse social groups into one homogeneous group which works together to achieve an allegedly shared goal. For example, in TheVillage by the Sea the protest movement of the locals is assimilated into a greater movement to protect the environment which is then co-opted by different organisations serving capitalist 
interests. The protesting locals are told by the organisers of the protest to put aside their differences and come together for resisting the building of the unit. The organisers' team includes people who are against the construction of the factory for the sole reason that it would destroy their means of production and they are not really concerned with the environment, although that is the narrative they use to invite people to join their protest. Thus, the industrialists in the novel employ a universalising and homogenising narrative of global ecological preservation using Western notions of knowledge and science in order to further the capitalist narrative of the Global North.

In a similar fashion, in Thinner Than Skin the idea of universality and homogeneity is employed in the subjectivation of characters. Farhana and Nadir become complicit with the narrative of the West when they become knowledgegatherers for them. Farhana collected data about the glaciers which will provide the West with information regarding how the melting of the polar caps can be stopped. Khan points out in her novel, through the voice of Nadir, "Glaciers in the eastern Himalayas are receding. Some say the Alps will be ice-free by 2100 . Greenland's glaciers are melting so fast they could sink southern California and Bangladesh" (41). It was the Pakistani glaciers which were expanding and thus Farhana and Wes were there to explore. Thus by collecting knowledge of these Pakistani glaciers regarding what makes them expand instead of melt, and taking this knowledge back to the US, Farhana and Wes would then be using knowledge belonging to the Global South for the benefit of the Global North. Nadir, on the other hand, is collecting photographs which will provide a new batch of knowledge about Pakistan to the US. For this purpose, their national identity becomes irrelevant as their aim is concerned with an issue that is spread on a global scale. The Global North therefore recruits them as native informers who allow for the perpetuation of the dominant position of the West. They work under the veil of authenticity by claiming a knowledge-based authority over their native land, thus informing the West of what they need to know.

Additionally, in playing with their ambiguous national identities via neoorientalism, eco-imperialism allows for the creation of the illusion of a seemingly all-inclusive group which serves global interests, while in reality, it is merely serving the interests of the Global North. In creating this homogenised group, it provides Farhana and Nadir with a sense of belonging and fixed identity. Despite their having submerged themselves in the capitalist society of the Global North, we see that there is still a lingering sense of a lack of belonging experienced by these two characters. They are never able to fully integrate into the Western soci- 
ety in which they live, as that society refuses to accept them as their own. This is obvious in Farhana who repeatedly oscillates between her Pakistani and American identity. In some instances, she refers to Pakistan as a place where she is to return thus giving it a semblance of home, while in others she takes up the role of the American tourist who is not aware of the realities of Pakistan. For instance, she once tells Nadir that he should have told her about the conditions of the locals, "I would have brought some supplies" (Khan 60). Their identity and longing for a home folds into the narratives of knowledge, environmentalism and neoliberalism and has become complicit with the re-orientalisation of Pakistan's northern areas as simple, backward societies that require a patronage and guidance from the likes of Farhana.

Going forward, I explore how not only is the environmentalist movement re-propagating the orientalist conception of the Global South, but also how, through this movement, the locals are deprived of their environment by severing their relation to it.

\section{Biopiracy: Robbing the Natives of their Environment}

Making use of biopiracy, neo-colonialism also perpetuates bio-colonialism through the robbing of indigenous material resources. Both Desai and Khan highlight the way bio-colonialism, operating through biopiracy, induces ruptures in the ecological balance, that is, depriving the locals of their environment as their land, which is their main source of livelihood. It consequently leaves them with no other option but to head to the cities in search of jobs. The environmentalist agenda employs the robbing of the biological resources and their related knowledge (Shiva 152) to subjugate and displace the Indigenous people in developing countries like Pakistan. This act of biopiracy is reflected in both novels. In The Village by the Sea we see that the natives, due to the construction of the fertiliser unit, will lose their fertile land and water which was their source of sustenance. A villager asks, "[w]hat will happen to the hill and the temple on top?"The reply he received was "they will cut it down . . . make it all flat. Build the factory on top." He then wonders, "How could the hill and the temple disappear? It had been there all his life and his father's and grandfather's as well" (Desai 13-14). This fertiliser unit was going to rob the villagers of a home which for them was no less than a living being; one instance in the novel we see it being described as "the voice of the village Thul as much as the roar of the waves and the wind of the palms. It seemed to tell Lila to be calm and happy and all would be well and all would be just as it was before." (Khan 5). The fertiliser unit was thus going to rob 
the locals of the place which for them was the source of comfort amongst all the harsh social and economic difficulties they faced.

On the other hand, in Thinner than Skin, Nadir's camera becomes the tool with which he commits the act of stealing on the symbolic level. Throughout the novel, the camera and the act of taking pictures recur multiple times in order to represent the idea of appropriating information about the locals. Biopiracy involves the stealing of the local knowledges to help western discourses co-opt and assimilate them to reinforce their intellectual and epistemological superiority. This is how Nadir acts as an accomplice. The camera and its ability to generate analysable data, that is, knowledge, is a means of the manipulation of Indigenous knowledge. When Nadir meets Farhana's father, their conversation on photography and painting reflects this: "Every picture tears the body from the soul. He [Farhana's grandfather] saw paintings and photographs as theft, a way of owning and even destroying everyone else" (Khan 53). Photography, thus, is represented as an insidious act and is also referred to as a "fascist eye". (Khan 53). According to Farhana's grandfather, it was through this fascist eye that the First World viewed the Third World. Instead of it being a mere glance directed at the Third World, it was a fierce gaze, what the grandfather called "ghoorna" (Khan 53). This ghoorna is now done by Nadir through his camera's gaze and becomes an act of biopiracy. He views Pakistan through the fascist eye of the West. This fascist eye of the West is inherently neo-colonial in nature as it looks down on Pakistan from a dominating perspective. Farhana's grandfather's fate also foreshadows Nadir's end. After serving in the British army, Farhana's grandfather returned to his native country only to be constantly under the gaze of the locals. "He returned both decorated and humiliated" (Khan 54). This is similar to what happened to Nadir and Farhana who, upon their return to their homeland, were not welcomed but were treated as intruders. This is further evident in the novel when we come to know that the locals have changed their customs of hospitality and do not treat guests in the same welcoming manner as they used to (Khan 69). As Irfan elaborates in the novel that "[h]ard times make hard people," [he] continued. "These herders would normally never turn away a guest, but they won't host someone who'll bring in the ISI, though they fear it may already be so late. Anyone could be a spy. Including a tourist. They want the tourists to leave. It isn't like them" (Khan 6970). Their reason for discarding their customs and traditions of hospitality is the intrusion of foreign individuals like Farhana and her team as well as the terrorists. These intruders do not only disturb their lives but also pose a threat to their ways of living and their environment.

6 Urdu word which means to stare or gaze intensely and fiercely. 
What we have here, then, is the conclusion that environmentalism, understood in the context of neo-colonialism, is a movement which allows for the perpetuation of Eurocentric ideals of capitalism in the Global South while also furthering the profits of the Global North. In the contemporary era, colonialism is still prevalent, camouflaging itself under the guise of homogenising and universalising movements such as environmentalism. By employing these homogenising movements, the Global North continues its domination over the nations of the Global South while at the same time it furthers its own capitalist interests. It is concluded that in order to perpetuate neo-colonialism, eco-imperialism employs universalising and homogenising narratives of global ecological preservation in order to dominate the nations of the Global South. In eco-imperialist discourse, a hierarchy is created between Western conceptions of knowledge and the forms of knowledges native to the Global South. Through this hierarchisation, the Western knowledges are privileged while other forms of knowledges are demarcated to the periphery and deemed inauthentic. Thus, eco-imperialism operates through the discarding or dismantling of Indigenous knowledges in favour of Western knowledges. The Eurocentric forms of knowledge are presented as authentic and shown to have more value than the Indigenous forms of knowledges. 


\section{Works Cited}

Beinart, William, and Lotte Hughes. Environment and Empire. Oxford: Oxford University Press, 2007.

Castro-Gómez, Santiago. "The Missing Chapter of Empire: Postmodern Reorganisation of Coloniality and Post-Fordist Capitalism." Cultural Studies 21.2-3 (2007): 428-448.

Cribb, Robert. "Conservation in Colonial Indonesia." Interventions, vol. 9, no. 1, pp. 49-61.

Desai, Anita. TheVillage by The Sea. New Delhi: Puffin Books, 1982.

DeLoughrey, Elizabeth, and George B. Handley, eds. Postcolonial Ecologies: Literatures of The Environment. OUP USA, 2011.

Driessen, Paul. Eco-Imperialism Green Power, Black Death. Virginia: Free Enterprise Press, 2010.

Dutta, Swarup. "Green Revolution Revisited: The Contemporary Agrarian Situation in Punjab, India.”Social Change 42.2 (2012): 229-247. Jadhav, Rajendra, and Mayank Bhardwaj. "After Monsanto Patent Ruling, Indian Farmers Hope for next-Gen GM Seeds.” Reuters, Thomson Reuters, 11 Jan. 2019.

Khan, Uzma. Thinner Than Skin. New Delhi: Interlink Publishing, 2012. Maldonado-Torres, Nelson. “Colonialism, Neocolonial, Internal Colonialism, The Postcolonial, Coloniality, And Decoloniality." Critical Terms in Caribbean And Latin American Thought. Palgrave Macmillan, New York, 2016. 67-78.

Mignolo, Walter D. "Epistemic Disobedience, Independent Thought and Decolonial Freedom.” Theory, Culture \& Society 26.7-8 (2009): 159-181.

Rowlatt, Justin. "IR8: The Miracle Rice Which Saved Millions of Lives.” BBC News, BBC, 1 Dec. 2016.

Roy, Arundhati. My Seditious Heart: Collected: Non-Fiction. Chicago: Haymarket Books, 2019.

Shiva, Vandana. Biopiracy: The Plunder of Nature and Knowledge. New York: South End Press, 1997.

---. "How Monsanto Is Getting Away With Looting India's Farmers". 13 Mar. 2013. www.aljazeera.com/indepth/opinion/2013/03/ 201332813553729250.html. 15 March 2019.

Soomin, Lim, and Steven Shirley. "Eco-Imperialism: The Global North's Weapon of Mass Intervention." Journal of Alternative Perspectives in the Social Sciences 1.3 (2009): 846-860. 
Thrift, Nigel. Knowing Capitalism. Sage, 2005.

Tlostanova, Madina, and Walter Mignolo. "Global Coloniality and the Decolonial Option.” Kult 6. Special Issue (2009): 130-147.

Tynan, Aidan. "Desert Earth: Geophilosophy and the Anthropocene." Deleuze Studies 10.4 (2016): 479-495.

Whitt, Laurelyn. Science, Colonialism, and Indigenous Peoples: The Cultural Politics of Law and Knowledge. Cambridge: Cambridge University Press, 2009. 